\author{
Robyn Stobbs \\ School of Library and Information Studies and Department of Human Ecology, University \\ of Alberta, Edmonton, AB, Canada
}

\title{
Narratives of Fact and Fiction: Examining Studies of Information Experience and the Interpretation of Data (Paper)
}

\begin{abstract}
Résumé:
This paper reports on an ongoing pilot study of creative engagement with fictional worlds in order to explore potential contributions of narrative methods and data to the investigation of information behaviour and experience in LIS. A narrative framework can be used to examine the individual, social, and material aspects of information experiences situated in time and space. Such a framework has the potential to contribute detailed understandings of the nature of the experience of information and fiction, and of information experience more generally, to the body of literature on information experience in LIS.
\end{abstract}

\section{Introduction}

Narrative, information, and data play a role in people's everyday lives and understandings. Polkinghorne (1988) describes narrative as "the primary form by which human experience is made meaningful" (p. 1). The purpose of this paper is to explore information experiences related to fiction and the use of narrative methods and data for their study. Narrative methods provide an avenue to examine the individual, social, and material aspects of information experiences situated in time and space. I am currently conducting a pilot study of readers' / fans' / audiences' information experiences and engagements with fictional worlds. The pilot study specifically employs narrative methods to examine individual creative engagements with fictional worlds and their associated information practices. In connection to the conference theme of data, this paper uses the pilot study's emerging analysis of the case of M.B. and her creative engagement with LARP (Live Action Roleplay) to discuss the potential for narrative data and inquiry to contribute to the study of information practices and experiences.

\section{Literature Review}

The pilot study I discuss in this paper is situated in the research area of information behaviour and experience in LIS. Within that realm, fiction and fandom are an understudied and emerging area (Doty \& Broussard 2017, Forcier 2017, Price \& Robinson 2017). The topic of fiction and information behaviour could be analyzed through frameworks of serious leisure, such as those discussed by Stebbins (2009) and Hartel (2003). Information behaviour, as it pertains to fiction, has been investigated through studies of information seeking in the contexts of book selection 
and access (Mikkonen \& Vakkari 2016, 2017; Moyer 2007; Ooi \& Liew 2011; Saarinen \& Vakkari 2013); through the information found when reading, intentionally or incidentally, (Ross 1999, p. 794-795); negotiation of sexual identities (Rothbauer 2004b, 2004a); how fiction serves as a "roadmap" to inform real life situations (Broussard \& Doty 2016, Doty \& Broussard 2017); or more generally, how fiction reading serves other educational, recreational, or personal outcomes (Moyer 2007, Stobbs 2014). The study of fiction and information can add to the bodies of literature on serious leisure and information behaviour, but it can also expand and connect to discussions of information experience more broadly.

Information experience is a holistic concept that can be approached from various perspectives; it can encompass emotional, embodied, and other aspects of information use that go beyond seeking or skills and behaviours (Bruce, Davis, Hughes, Partridge, \& Stoodley 2014, p. 8). The argument that fiction can inform (Broussard \& Doty 2016, Doty \& Broussard 2017), combined with the concept of information experience, frames this paper and my exploration of narrative methods and data as a way to understand information experiences related to fiction.

Narrative methods have not been widely used in studies of information behaviour or experience. My initial literature review found very few examples. One study focused on methods of narrative interviewing (Bates 2004), and I found a few studies using narrative methods to investigate information behaviour in specific contexts: personal health management (Genuis 2015), students seeking job information (Hultgren 2013), first time mothers (Loudon, Buchanan, \& Ruthven 2015), and engineers (du Preez \& Meyer 2016). This paper demonstrates ways narrative methods can be used to study information experiences related to fiction, which provide insight into how narrative data and frameworks can be used to study information experience in general.

\section{Method: Narrative Inquiry}

My ongoing pilot project is a test of narrative methods to see the level of detail that can be obtained in data on creative engagements with fictional worlds and how those engagements may circulate, create, and document information experiences. These experiences may move beyond the borders of the imaginary world to expand or change it through the information practices of its audience. Individual audience members create and interact with material traces of fiction, and it is those traces and narratives about them that are being collected.

The research framework begins with narrative both as a part of the subject of study (e.g., as a source of information on fictional worlds) and as a methodological and theoretical frame. Narrative inquiry as described by Clandinin and Connelly (2000) is a way to garner extended understandings of experiences which are collected and analyzed through narrative methods. As such, a detailed, case-centred approach is common in narrative inquiry (Riessman 2008, p. 11).

I use a "three-dimensional narrative inquiry space," as described by Clandinin and Connelly (2000), for the study of human experience. The dimensions include: interaction (personal and social), continuity (time), and situation (context) (p. 50). These dimensions serve as guides to explore participants' experiences of information and making related to fictional worlds in-depth. To gain this depth, a small sample of five participants were recruited, and narrative methods influenced by ethnography and other forms of naturalistic inquiry are being employed to collect 
and analyze data. These methods include: observation, interviews, and object analyses of participants' creations. Analysis of this variety of narrative data types is providing nuanced research narratives of how fictional worlds and information can become materially situated in people's real lives.

Each participant chose a fictional world or project to talk about. I then began with an object elicitation interview with each participant, and I followed up with further participation options dependent upon what types of making and fictional world each participant chose to talk about. This method encourages on-going storytelling and interaction to generate more nuanced narratives of experience. For their initial interviews, participants brought both objects they have made and objects they use when engaging with the fictional world they chose. They were invited to talk about the objects they brought and how they use them.

As a part of the data analysis, participant and researcher narratives are being written to demonstrate the co-construction of concepts in the data collection process. These narratives are interim texts that are a part of the analysis process. The emerging narratives from this study will serve as examples of the ways in which narrative data and analysis can contribute to the body of knowledge in LIS on fiction-related information behaviours.

\section{Emerging Narratives of Information Experience}

This paper includes examples of data and stories collected with M.B., a participant who chose to talk about LARPing. M.B. makes both costume pieces and boffer weapons (foam weapons) for LARP. She brought a hockey bag full of pieces to her first interview, and she has since followed up by sending me pictures and previously written character backstories. The objects grounded our interview and worked as prompts for M.B.'s storytelling.

M.B. described materials and research used for creating a costume. For example, the following quote is a portion of her explanation of her current project, which is scale mail armour: "A lot of reenactment sites, and, uh, some history sites. There was a lot of options for the scale and the most common scale found used much smaller scales, about a centimetre across. I didn't have a supply for that available..." She makes compromises for the availability and cost of materials to meet her vision. She also uses historical information to inform her creation of a costume that fits the character she will play in the LARP world. She has a character in mind as she is making a piece; however, her pieces can be recombined and re-purposed as needed because they represent a significant investment in time and money.

Creating and playing a character requires not only investment of time and materials for M.B., it is also an opportunity to craft an experience that requires knowledge of LARP, the particular world the LARP takes place in, the real-world setting, game rules, and M.B.'s own goals. M.B.'s anecdotes and explanations of her costume pieces exemplify the depth of detailed data that can be collected through narrative inquiry. Her creations are a part of her embodied experience of information and the LARP world in context. For example, M.B. described how aluminum scale does not have the same sound as bronze, but it is more cost effective. M.B's experience is complex, involving individual aspects, such as her personal goals; social aspects, such as the rules for the particular LARP that are shared with other players; and her physically situated 
costume and location in tandem with the imaginary LARP location. The borders between the imaginary and the material are blurred as both contribute to the creative engagement with the LARP world.

\section{Discussion \& Conclusion: Narratives of Fact and Fiction}

There is an interaction between information, imagination, and the material world when a person engages with fictional worlds. Qualitative data, such as the narrative data in this study, can be used to provide windows into individual experiences in individual, social, and material contexts. Narrative can be a source of fact and fiction, and in studies of serious leisure and information behaviour relating to fictional narratives, it can not only be the data, but also the outcome. This paper is an interim research narrative put together to interpret narrative methods and data to move towards a better understanding of information experiences involving fiction. Further research will examine how fictional worlds become a part of information experience and inform individual realities. Narrative data and analysis can provide insight into the information experiences involved in engagements with fictional worlds and their borders with reality.

\section{Reference List:}

Bates, J. A. (2004). Use of narrative interviewing in everyday information behavior research. Library \& Information Science Research, 26(1), 15-28. https://doi.org/10.1016/j.lisr.2003.11.003

Broussard, R., \& Doty, P. (2016). Toward an understanding of fiction and information behavior. Proceedings of the Association for Information Science \& Technology, 53(1), 1-10. https://doi.org/10.1002/pra2.2016.14505301066

Bruce, C., Davis, K., Hughes, H., Partridge, H., \& Stoodley, I. (2014). Information experience: Contemporary perspectives. In Library and Information Science (Vol. 9, pp. 3-16). Bingley: Emerald Group Publishing. https://doi.org/10.1108/S1876056220140000010001

Clandinin, D. J., \& Connelly, F. M. (2000). Narrative inquiry: Experience and story in qualitative research (1st ed.). San Francisco, CA: Jossey-Bass Inc.

Doty, P., \& Broussard, R. (2017). Fiction as informative and its implications for information science theory. Proceedings of the Association for Information Science \& Technology, 54(1), 61-70. https://doi.org/10.1002/pra2.2017.14505401008

du Preez, M., \& Meyer, H. W. J. (2016). Consulting engineers' social networks and their collaborative information behaviour. Information Research, 21(4), 1-23.

Forcier, E. (2017). Re(a)d wedding: A case study exploring everyday information behaviors of the transmedia fan. Proceedings of the Association for Information Science \& Technology, 54(1), 93-101. https://doi.org/10.1002/pra2.2017.14505401011 
Genuis, S. K. (2015). "The transfer of information through word of mouth is powerful": Interpersonal information interactions. Information Research, 20(1), 126-139.

Hartel, J. (2003). The serious leisure frontier in library and information science: Hobby domains. Knowledge Organization, 30(3/4), 228-238.

Hultgren, F. (2013). The stranger's tale: information seeking as an outsider activity. Journal of Documentation, 69(2), 275-294. https://doi.org/10.1108/00220411311300075

Loudon, K., Buchanan, S., \& Ruthven, I. (2015). The everyday life information seeking behaviours of first-time mothers. Journal of Documentation, 72(1), 24-46. https://doi.org/10.1108/JD-06-2014-0080

Mikkonen, A., \& Vakkari, P. (2016). Readers' interest criteria in fiction book search in library catalogs. Journal of Documentation, 72(4), 696-715. https://doi.org/10.1108/JDOC-112015-0142

Mikkonen, A., \& Vakkari, P. (2017). Reader characteristics, behavior, and success in fiction book search. Journal of the Association for Information Science and Technology, 68(9), 2154-2165. https://doi.org/10.1002/asi.23843

Moyer, J. E. (2007). Learning from leisure reading: A study of adult public library patrons. Reference \& User Services Quarterly, 46(4), 66-79.

Ooi, K., \& Liew, C. L. (2011). Selecting fiction as part of everyday life information seeking. Journal of Documentation, 67(5), 748-772. http://dx.doi.org.login.ezproxy.library.ualberta.ca/10.1108/00220411111164655

Polkinghorne, D. (1988). Narrative knowing and the human sciences. Albany, NY: State University of New York Press.

Price, L., \& Robinson, L. (2017). 'Being in a knowledge space': Information behaviour of cult media fan communities. Journal of Information Science, 43(5), 649-664. https://doi.org/10.1177/0165551516658821

Riessman, C. K. (2008). Narrative methods for the human sciences. Los Angeles: Sage Publications.

Ross, C. S. (1999). Finding without seeking: the information encounter in the context of reading for pleasure. Information Processing \& Management, 35(6), 783-799. https://doi.org/10.1016/S0306-4573(99)00026-6

Rothbauer, P. (2004a). Finding and creating possibility: Reading in the lives of lesbian, bisexual and queer young women (Ph.D.). The University of Western Ontario (Canada), Canada. Retrieved from 
http://search.proquest.com.login.ezproxy.library.ualberta.ca/pqdtft/docview/305083607/a bstract/13970363CEE471949B9/1?accountid=14474

Rothbauer, P. (2004b). "People aren't afraid anymore, but it's hard to find books": Reading practices that inform the personal and social identities of self-identified lesbian and queer young women. Canadian Journal of Information \& Library Sciences, 28(3), 53-74.

Saarinen, K., \& Vakkari, P. (2013). A sign of a good book: readers' methods of accessing fiction in the public library. Journal of Documentation, 69(5), 736-754. https://doi.org/10.1108/JD-04-2012-0041

Stebbins, R. A. (2009). Leisure and its relationship to library and information science: Bridging the gap. Library Trends, 57(4), 618-631.

Stobbs, R. E. (2014). Fiction \& information: The leisure reading experience (unpublished). University of Alberta, Edmonton, Canada. Retrieved from https://era.library.ualberta.ca/files/j67314780\#.Vlf0r9-rSb8 